(с) Коллектив авторов, 2021

Сизякина Л.П. ${ }^{1}$, Закурская В.Я. ${ }^{1}$, Скрипкина Н.А. ${ }^{2}$, Антонова Е.А. ${ }^{2}$

Уровень ферритина как предиктор тяжелого течения COVID-19

Федеральное государственное бюджетное образовательное учреждение высшего образования «Ростовский государственный медицинский университет» Министерства здравоохранения Российской Федерации, 344022, г. Ростов-на-Дону, Российская Федерация

2 Муниципальное бюджетное учреждение здравоохранения «Городская больница № 1 им. Н.А. Семашко города Ростова-на-Дону», 344003, г. Ростов-на-Дону, Российская Федерация

\title{
Резюме
}

Введение. Поиск возможных прогностических критериев тяжести течения COVID-19 весьма актуален, так как он может оказать существенную помощь в выборе более эффективной и персонифицированной терапии. Степень остроты инфекционного процесса отражают острофазные белки, в частности ферритин. Степень информативности оценки его уровня в качестве прогностического критерия дискуссионна, что и определило цель данного исследования.

Цель - выявить клинико-иммунологические особенности течения COVID-19, формирующиеся при различных уровнях ферритина у пациентов со среднетяжелым вариантом течения.

Материал и методы. В исследование включали пациентов со среднетяжелой формой COVID-19 (43 человека), которые впоследствии были разделены на две группы: лица с высоким уровнем ферритина - 1744 мкг/л $[985,75 ; 2402,85]$ (22 человека) и с его нормальным содержанием - 264,4 мкг/л [129,5; 375,6] (21 человек). Группу сравнения составили практически здоровые доноры (31 человек). Забор крови для проведения общеклинического и биохимического анализа проводили на 2-3-и сутки с момента поступления пациента в лечебное учреждение. Содержание лимфоцитов, экспрессирующих популяционные рецепторы (CD3, CD4, CD8, CD16, CD19), оценивали методом проточной цитофлуориметрии, содержание сывороточных $\operatorname{IgA}, \operatorname{IgM}, \operatorname{IgG}$ - методом радиальной иммунодиффузии в геле по Манчини. Всем участникам исследования проводили компьютерную томографию органов грудной клетки.

Результаты. В группе пациентов с высоким уровнем ферритина отмечались лимфопения, повышение уровня С-реактивного белка и активная пролиферация CD19лимфоцитов без усиления процессов антителогенеза. Клинические проявления у данной группы пациентов были тяжелее, чем в группе с нормальным содержанием ферритина.

Заключение. Повышение уровня ферритина крови у пациентов со среднетяжелыми формами COVID-19 является предиктором более тяжелого течения и сопровождается нарушением процессов созревания Т-клеточного звена адаптивного иммунитета и усиленной пролиферацией В-лимфоцитов без адекватного усиления процессов антителогенеза. Ключевые слова: коронавирусная инфекция; COVID-19; ферритин

Статья получена 16.04.2021. Принята в печать 17.06.2021.

Для цитирования: Сизякина Л.П., Закурская В.Я., Скрипкина Н.А., Антонова Е.А. Уровень ферритина как предиктор тяжелого течения COVID-19. Иммунология. 2021; 42 (5): 518-525. DOI: https://doi.org/10.33029/02064952-2021-42-4-518-525

Финансирование. Исследование не имело спонсорской поддержки.

Конфликт интересов. Авторы заявляют об отсутствии конфликта интересов

Sizyakina L.P. ${ }^{1}$, Zakurskaya V.Ya. ${ }^{1}$, Skripkina N.A. ${ }^{2}$, Antonova E.A. ${ }^{2}$

\section{Ferritin level as a predictor of COVID-19 severe course}

Rostov State Medical University of the Ministry of Health of the Russian Federation, 344022, Rostov-on-Don, Russian Federation

${ }^{2}$ City Hospital No. 1 named after N.A. Semashko of Rostov-on-Don, 344003, Rostov-on-Don, Russian Federation 


\section{Abstract}

Introduction. The search for possible prognostic criteria for the severity of COVID-19 is very relevant, as it can provide significant assistance in choosing a more effective and personalized therapy. The degree of severity of the infectious process is reflected by acute-phase proteins, in particular ferritin. The degree of informative assessment of its level as a predictive criterion is debatable, which determined the purpose of this study.

Aim of the study - to reveal the clinical and immunological features of the course of COVID-19 in patients with a moderate variant of the course, depending on the level of ferritin.

Material and methods. The study included patients with moderate COVID-19 (43 patients), who were subsequently divided into two groups: with high ferritin levels $-1744 \mathrm{mcg} / \mathrm{l}$ [985.75; 2402.85] (22 patients) and with normal ferritin levels - $264.4 \mathrm{mcg} / 1$ [129.5; 375.6] (21 patients). The group of comparison consisted of practically healthy donors (31 persons). Blood samples was taken for 2-3 days from the moment of admission for general clinical and biochemical analysis. $\mathrm{CD}^{+}-, \mathrm{CD}^{+}-, \mathrm{CD}^{+}-, \mathrm{CD} 16^{+}$- and $\mathrm{CD} 19^{+}$-lymphocytes were evaluated by flow cytofluorimetry, as well as the level of serum $\operatorname{IgA}$, IgM and $\operatorname{IgG}$ - by radial gel immunodiffusion by Mancini. A computer tomography of the chest organs was performed for all study participants.

Results. Lymphopenia, increased levels of C-reactive protein, and active proliferation of CD19+-lymphocytes without increased antibody production were observed in the group of patients with high ferritin levels. Clinical manifestations in this group of patients are more severe than in the group with normal ferritin content.

Conclusion. An increase of the blood ferritin level in patients with moderate COVID-19 is a predictor of a more severe course and is accompanied by a violation of the maturation of the T-cell part of adaptive immunity and increased proliferation of B-lymphocytes without an adequate increase of antibody formation processes.

Keywords: coronavirus infection; COVID-19; ferritin

Received 16.04.2021. Accepted 17.06.2021.

For citation: Sizyakina L.P., Zakurskaya V.Ya., Skripkina N.A., Antonova E.A. Ferritin level as a predictor of COVID-19 severe course. Immunologiya. 2021; 42 (5): 518-25. DOI: https://doi.org/10.33029/0206-4952-2021-42-4-518-525

Funding. The study had no sponsor support.

Conflict of interests. The authors declare no conflict of interests.

\section{Введение}

Пандемия COVID-19 - заболевания, вызываемого новой коронавирусной инфекцией SARS-CoV-2, стала настоящей «чумой XXI века» для всех стан мира. Согласно официальным данным Всемирной организации здравоохранения (ВО3), к середине марта 2021 г. только в европейском регионе выявлено и подтверждено более 43 млн случаев COVID-19. Из них свыше 900 тысяч завершились летальным исходом [1]. Для COVID-19 характерны высокая активность воспаления и тромботические осложнения, приводящие к полиорганным поражениям [2, 3]. И хотя самым частым проявлением COVID-19 является поражение дыхательной системы, ведение пациента с этим заболеванием подразумевает не только лечение пневмонии и дыхательной недостаточности, но и своевременное распознавание и лечение других пораженных органов-мишеней $[4,5]$. Поиск возможных прогностических критериев течения COVID-19 по-прежнему актуален, так как он обусловливает необходимость выбора более эффективного комплекса терапевтических мероприятий в каждом конкретном случае [6]. В частности, отмечена корреляция между тяжелым течением заболевания и уровнем острофазных белков. Так, высокий уровень С-реактивного белка (СРБ) свидетельствует о тяжелом течении [7,8].

Не менее интересна динамика другого белка острой фазы с выраженными цитотоксическими эффектами ферритина. Это водорастворимый белок с молекулярной массой 400-440 кДа, способный присоединять до 4500 атомов железа, что и является его важнейшей биологической функцией $[9,10]$. Однако взаимосвязи клинических и иммунологических показателей с уровнем ферритина дискуссионны $[11,12]$. Оценка значения ферритина как прогностического биомаркера при COVID-19 является актуальной задачей.

Цель исследования - изучить клинико-иммунологические особенности течения COVID-19 у пациентов со среднетяжелым вариантом заболевания в зависимости от уровня ферритина.

\section{Материал и методы}

Участники исследования. В исследование были включены пациенты, получавшие лечение в моноинфекционном госпитале МБУЗ ГБ № 1 им. Н.А. Семашко Ростова-на-Дону с основным диагнозом при по- 
ступлении: COVID-19 (подтверждено), среднетяжелая форма. Всего под наблюдением находилось 43 пациента (19 мужчин и 24 женщины, средний возраст - 61,1 \pm 14 год). Группу сравнения составили соотносимые по возрасту практически здоровые доноры (31 человек). Клиническое исследование выполнено в соответствии с Хельсинской декларацией Всемирной медицинской ассоциации «Этические принципы проведения научных медицинских исследований с участием человека» с поправками 2000 г., WMA Declaration of Helsinki - Ethical Principles for Medical Research Involving Human Subjects (2013), Правилами клинической практики в Российской Федерации, утвержденными приказом Минздрава России от 19.06.2003 № 266. Все пациенты подписывали добровольное информированное согласие на участие в исследовании.

Лабораторные исследования. У каждого пациента был собран анамнез. Забор крови для исследования проводили однократно на 2-3-и сутки с момента госпитализации. В общеклиническом анализе крови оценивали содержание эритроцитов, уровень гемоглобина, гематокрит, тромбокрит, а также общее количество лейкоцитов с лейкоцитарной формулой. Биохимические показатели включали определение СРБ, ферритина, АлТ, АсТ, альбумина, мочевины, креатинина, глюкозы, лактатдегидрогеназы (ЛДГ), общего белка, амилазы, билирубина.

С помощью проточной цитофлуориметрии определяли экспрессию маркеров Т-клеток (CD3, CD4, CD8), B-клеток (CD19) и натуральных киллерных клеток (НКклеток) (CD16). Содержание сывороточных $\operatorname{IgA}, \operatorname{IgM}$, $\mathrm{IgG}$ выявляли с помощью радиальной иммунодиффузии по Манчини.

Также у всех пациентов оценивали степень поражения легочной ткани методом компьютерной томографии (КТ). Все пациенты получали терапию согласно текущим временным методическим рекомендациям по лечению COVID-19 (9-я версия).

Статистический анализ. Статистическая обработка данных проведена с использованием программы
Statistica 10 (StatSoft Inc., США). Описательную статистику количественных признаков представляли в виде центральной тенденции медианы и межквартильного размаха (25-й и 75-й процентили), представлено в тексте как Me [LQ; UQ]. Сравнение медиан в группах осуществляли с помощью теста Манна-Уитни. Различия признавались статистически значимыми на уровне $p<0,05$. Значимость расхождения частоты встречаемости различных симптомов и состояний у пациентов оценивалась при помощи теста $\chi^{2}$ с оценкой критерия согласия Пирсона $\chi^{2}$. Различия признавались достоверными для уровня значимости $p<0,05$.

\section{Результаты}

Пациенты поступали в среднем на 6-7-е сутки от начала заболевания и находились в отделении 15,3 [14; 19] дней. Некоторым пациентам (8 человек, 18,75 \%) в силу утяжеления состояния потребовался перевод в реанимационное отделение, срок нахождения в котором составлял $8,5[7,5 ; 9,5]$ дней.

При анализе предъявляемых жалоб оказалось, что самым частым симптомом у пациентов является лихорадка (41 человек, 95,3 \%), малопродуктивный кашель встречался у 33 человек (76,7 \% случаев), а одышка и потребность в кислороде - у 21 человека (48,8 \%). Примерно с равной частотой пациентов беспокоили симптомы интоксикации, включавшие головные боли, головокружение, нарушение сна (у 16 человек, 37,5 \%), потерю вкуса и обоняния (у 13 человек, 30,2 \%) и признаки поражения желудочно-кишечного тракта (тошнота, жидкий стул) - у 17 человек (39,5 \%).

Всем пациентам, согласно действующим рекомендациям, выполняли КТ легких. Выявлена следующая картина поражения легочной ткани: КТ1 (поражение легких до $25 \%$ ) - у 4 человек (9\%); КТ2 (поражение легких 25-50 \%) - у 16 человек (38 \%); КТ3 (поражение легких 50-75\%) - у 23 человек (53\%).

Изменения в общеклиническом анализе крови у всех пациентов со среднетяжелой формой COVID-19

Таблица 1. Сравнительная характеристика биохимических показателей крови у пациентов со среднетяжелой формой COVID-19 и группы сравнения

\begin{tabular}{|l|c|c|c|}
\hline Показатель & Пациенты со среднетяжелым течением COVID-19 & Группа сравнения & $\boldsymbol{U}$-критерий \\
\hline Альбумин, г/л & $34[31 ; 35,1]$ & $38[34 ; 41]$ & $p>0,05$ \\
\hline АЛТ, Ед/л & $38,75^{*}[21,85 ; 65]$ & $22,4[17,5 ; 44,3]$ & $p<0,05$ \\
\hline АСТ, Ед/л & $34,35[24,33 ; 53,8]$ & $30[19,7 ; 41,6]$ & $p>0,05$ \\
\hline Мочевина, ммоль/л & $7,05[4 ; 9,6]$ & $5,9[3,1 ; 7,4]$ & $p>0,05$ \\
\hline Креатинин, мкмоль/л & $90[76 ; 105]$ & $84[61 ; 101]$ & $p>0,05$ \\
\hline Глюкоза, ммоль/л & $6,13 *[5,2 ; 8,2]$ & $5,6[4,8 ; 6,0]$ & $p<0,05$ \\
\hline СРБ, мг/мл & $19,2 *[6,2 ; 55,95]$ & $1,5[0,2 ; 5]$ & $p>0,05$ \\
\hline Общий белок, г/л & $67,85[63,1 ; 72,45]$ & $71,6[64,7 ; 78,5]$ & $p>0,05$ \\
\hline Амилаза, Ед/л & $48,5[29 ; 69,5]$ & $45[20 ; 78,4]$ & $p>0,05$ \\
\hline Билирубин, мкмоль/л & $7,2[4,95 ; 9,05]$ & $9,4[5,7 ; 14,9]$ & $p>0,05$ \\
\hline Ферритин, мкг/л & $443,7 *[259,6 ; 1337,15]$ & $94,7[18,4 ; 150]$ & $p<0,05$ \\
\hline
\end{tabular}

Примечание. Здесь и в табл. 2-6: * - статистическая значимость различий показателей между группами (р < 0,05), рассчитанная с учетом U-критерия Манна-Уитни; в таблице средние значения представлены в виде Ме [LQ; UQ]. Pасиифровку аббревиатур см. в тексте. 
Таблица 2. Сравнительная характеристика иммунологических показателей крови у пациентов со среднетяжелой формой COVID-19 и группы сравнения

\begin{tabular}{|c|c|c|c|}
\hline Показатель & Пациенты со среднетяжелым течением COVID-19 & Группа сравнения & $U$-критерий \\
\hline $\mathrm{CD}^{+}, \%$ & $72[60,5 ; 76]$ & $71[61 ; 74]$ & $p>0,05$ \\
\hline $\mathrm{CD}^{+}, \cdot 10^{9} / л$ & $0,89 *[0,67 ; 1,15]$ & $1,6[0,9 ; 1,8]$ & $p<0,05$ \\
\hline $\mathrm{CD}^{+}{ }^{+} \mathrm{CD} 4^{+}, \%$ & $43,5[38 ; 51,5]$ & $42[36 ; 44]$ & $p>0,05$ \\
\hline $\mathrm{CD}^{+} \mathrm{CD}^{+}, \bullet 10^{9} /$ л & $0,58 *[0,4 ; 0,88]$ & $0,8[0,6 ; 1]$ & $p<0,05$ \\
\hline $\mathrm{CD}^{+} \mathrm{CD}^{+}, \%$ & $22,5[16,75 ; 32]$ & $25[22 ; 31]$ & $p>0,05$ \\
\hline $\mathrm{CD}^{+} \mathrm{CD}^{+}, \bullet 10^{9} /$ л & $0,28 *[0,21 ; 0,47]$ & $0,46[0,3 ; 0,7]$ & $p<0,05$ \\
\hline ИРИ & $1,98[1,23 ; 2,93]$ & $1,8[1,3 ; 2,3]$ & $p>0,05$ \\
\hline $\mathrm{CD} 16^{+}, \%$ & $11[6,25 ; 18,75]$ & $12[8 ; 15,4]$ & $p>0,05$ \\
\hline $\mathrm{CD}_{16}{ }^{+}, \bullet 10^{9} /$ л & $0,18 *[0,1 ; 0,25]$ & $0,22[0,19 ; 0,34]$ & $p<0,05$ \\
\hline $\mathrm{CD}^{2} 9^{+}, \%$ & $14[9,25 ; 20,75]$ & $15[9 ; 17,9]$ & $p>0,05$ \\
\hline $\mathrm{CD}_{19}+\bullet 10^{9} /$ л & $0,17 *[0,11 ; 0,22]$ & $0,28[0,12 ; 0,31]$ & $p<0,05$ \\
\hline $\operatorname{IgA,~г/л~}$ & $2,18[1,56 ; 2,94]$ & $2[1,4 ; 2,5]$ & $p>0,05$ \\
\hline $\operatorname{IgM,~г/л~}$ & $0,91[0,77 ; 1,19]$ & $1,1[0,89 ; 1,4]$ & $p>0,05$ \\
\hline $\mathrm{IgG}$, г/л & $10,3[8,8 ; 11,8]$ & $11[9,5 ; 12,5]$ & $p>0,05$ \\
\hline
\end{tabular}

Примечание. Здесь и в табл. 6: ИРИ-иммунорегуляторный индекс.

в первую очередь характеризовались умеренной лимфопенией со снижением числа лимфоцитов в среднем до $21 \%$ [12; 34] в относительных значениях и до $1,3 \cdot 10 \%$ л $[1 ; 1,58]$ - в абсолютных, а также гранулоцитозом: $77 \%$ [61; 86] и 4,37 • 10\% /л [3,37; 8,24], моноцитопенией: $2,4 \%[1,6 ; 3,45]$ и $0,16 \cdot 109 / л[0,08 ; 0,28]$.

Характеризуя значимые изменения биохимических показателей крови пациентов, следует отметить повышение уровней СРБ и ферритина, что полностью согласуется с результатами ранее проводимых исследований (табл. 1).
В клеточном звене адаптивного иммунитета относительные показатели находятся в пределах нормы, однако при пересчете в абсолютные значения цифры были либо приближены к нижним границам, либо ниже нормы (табл. 2). Подобные изменения объясняются выраженной лимфопенией, сопровождающей COVID-19.

Безусловно, показатели иммунного статуса в большей части соответствуют возрастной норме, однако в данной ситуации на фоне активного инфекционного процесса следовало ожидать компенсаторной активации иммунологических механизмов защиты как в клеточном, так и в гуморальном звеньях.

Таблица 3. Сравнительная характеристика клинических показателей у пациентов со среднетяжелой формой COVID-19 в группах с высоким и нормальным уровнем ферритина

\begin{tabular}{|c|c|c|c|c|}
\hline Показатель & $\begin{array}{c}\text { Группа с высоким } \\
\text { уровнем ферритина }\end{array}$ & $\begin{array}{l}\text { Группа с нормальным } \\
\text { уровнем ферритина }\end{array}$ & $\chi^{2}$ & $p$ \\
\hline Возраст, годы & $65^{*}[56 ; 71]$ & $62,5[51,5 ; 72,25]$ & & $>0,05$ \\
\hline Длительность госпитализации, дни & $17[14 ; 18]$ & $14[13 ; 15]$ & & $>0,05$ \\
\hline $\begin{array}{l}\text { Потребность в переводе в реанимационное } \\
\text { отделение, абс. }\end{array}$ & 10 & - & & \\
\hline $\begin{array}{l}\text { Длительность нахождения в реанимационное } \\
\text { отделение, дни }\end{array}$ & $8,5 \pm 1,9$ & - & & \\
\hline \multicolumn{5}{|c|}{ Симптомь } \\
\hline Лихорадка, абс. (\%) & $21(95 \%)$ & $21(100 \%)$ & 0,08 & $>0,05$ \\
\hline Температура тела, ${ }^{\circ} \mathrm{C}$ & $38,4[37,5 ; 39,1]$ & $38,2[37,3 ; 38,9]$ & & $>0,05$ \\
\hline Кашель, абс. (\%) & $17(77 \%)$ & $19(90 \%)$ & 0,61 & $>0,05$ \\
\hline Одышка, абс. (\%) & $19 * *(86 \%)$ & $8(38 \%)$ & 13,31 & $<0,05$ \\
\hline Симптомы интоксикации, абс. (\%) & $15 * *(68 \%)$ & $2(9 \%)$ & 5,58 & $<0,05$ \\
\hline Потеря вкуса и обоняния, абс. (\%) & $6(27 \%)$ & $10(47 \%)$ & 1,57 & $>0,05$ \\
\hline Потребность в кислороде, абс. (\%) & $20 * *(90 \%)$ & $6(28 \%)$ & 18,43 & $<0,05$ \\
\hline Жидкий стул, абс. (\%) & $8(36 \%)$ & $9(42 \%)$ & 0,1 & $>0,05$ \\
\hline \multicolumn{5}{|c|}{ Картина КТ } \\
\hline КТ1, абс. (\%) & $0 * *$ & $5(23 \%)$ & 5,64 & $<0,05$ \\
\hline КТ2, абс. (\%) & $6 * *(27 \%)$ & $12(57 \%)$ & 3,38 & $<0,05$ \\
\hline КТ3, абс. (\%) & $16^{* *}(73 \%)$ & $4(20 \%)$ & 13,2 & $<0,05$ \\
\hline
\end{tabular}

Примечание. **-статистическая значимость различий показателей между группами $(p<0,05)$ рассчитанная с учетом критерия согласия Пирсона $\chi^{2}$. 
Tаблица 4. Сравнительная характеристика показателей общего анализа крови у пациентов со среднетяжелой формой COVID-19 в группах с высоким и нормальным уровнем ферритина

\begin{tabular}{|c|c|c|c|}
\hline Показатель & $\begin{array}{c}\text { Группа с высоким уровнем } \\
\text { ферритина }\end{array}$ & $\begin{array}{c}\text { Группа с нормальным уровнем } \\
\text { ферритина }\end{array}$ & $U$-критерий \\
\hline Лейкоциты, • $10^{9} /$ л & $7,35^{*}[4,47 ; 10,67]$ & $6,2[5 ; 9,55]$ & $p<0,05$ \\
\hline Эритроциты, • $10^{12} / л$ & $4,24[3,6 ; 4,7]$ & $4,44[4 ; 4,76]$ & $p>0,05$ \\
\hline $\mathrm{Hb}$, г/л & $128,5[117,5 ; 145,25]$ & $130[117,5 ; 142,5]$ & $p>0,05$ \\
\hline Гематокрит, \% & $35,5[32,33 ; 40,25]$ & $36,5[32,5 ; 39,5]$ & $p>0,05$ \\
\hline Тромбциты , $\bullet 10^{9} / л$ & $171,5[158,5 ; 219,5]$ & $172[152,5 ; 209]$ & $p>0,05$ \\
\hline Лимфоциты, \% & $13,7 *[9,05 ; 21,53]$ & $29,9[19,9 ; 37,65]$ & $p<0,05$ \\
\hline Лимфоциты, $\bullet 10^{9} /$ л & $1,2 *[0,81 ; 1,8]$ & $1,5[1,13 ; 2,3]$ & $p<0,05$ \\
\hline Моноциты, \% & $2,55[1 ; 4,9]$ & $2[1,85 ; 3,05]$ & $p>0,05$ \\
\hline Моноциты, $・ 10^{9} / л$ & $0,17[0,09 ; 0,23]$ & $0,12[0,09 ; 0,26]$ & $p>0,05$ \\
\hline Гранулоциты, \% & $82 *[76 ; 90]$ & $67,7[60,6 ; 76,7]$ & $p<0,05$ \\
\hline Гранулоциты, • 109/л & $5,79 *[4 ; 9,2]$ & $4,0,6[3,3 ; 6,3]$ & $p<0,05$ \\
\hline
\end{tabular}

Несмотря на то что все пациенты поступили в отделение с одинаковой степенью тяжести заболевания, их лабораторные показатели значительно варьировали. В первую очередь обращал на себя внимание уровень ферритина крови, который у одних пациентов был значительно выше возрастной нормы, а у других оставался в пределах референсных значений (от 20 до 400 мкг/л). В зависимости от этого обследуемые пациенты были распределены на 2 группы: с высоким содержанием ферритина 1744 мкг/л [985,75; 2402,85] (22 человека) и с его нормальным содержанием 264,4 мкг/л [129,5; 375,6] (21 человек).

Анализ клинического течения COVID-19 у пациентов с высоким уровнем ферритина выявил, что длительность госпитализации у них в среднем была на 3 дня больше. Необходимость перевода в анестезиолого-реанимационное отделение была только у этих пациентов, что объясняет более тяжелый характер протекания инфекции Симптомы одышки, интоксикации, потребность в оксигенотерапии значительно чаще встречается у больных с высокими значениями уровня ферритина. При КТ легких объем поражения легочной паренхимы больше в группе пациентов с высоким содержанием ферритина (табл. 3).

В показателях общеклинического анализа крови значимые изменения заключались в большем содержании лейкоцитов, значительной лимфопении и выраженном гранулоцитозе у пациентов в группе с высоким содержанием ферритина, следует отметить моноцитопению одинаково характерную для пациентов в обеих группах, что может свидетельствовать о выраженных дисрегуляторных процессах в системе врожденного иммунитета (табл. 4).

В биохимических показателях крови между пациентами 2 групп статистически значимые отличия в первую очередь заключатся в различном содержании СРБ (в 5 раз выше в группе с высоким уровнем ферритина). В группе с нормальным уровнем ферритина показатели белкового обмена выше, как и уровень амилазы крови, они соответствуют возрастной норме. Снижение уровня общего белка в группе с высоким уровнем ферритина вероятно происходит за счет глобулиновой фракции и является предиктором более тяжелого течения COVID-19 и высокого риска присоединения вторичной бактериальной инфекции (табл. 5).

Анализ показателей иммунного статуса выявил, что среднетяжелые формы COVID-19 у пациентов с нормальным содержанием ферритина характеризуются более высоким содержанием Т-лимфоцитов как в относительных, так и в абсолютных значениях. При этом следует отметить более высокое содержание $\mathrm{CD}^{+}-\mathrm{T}$ -

Таблица 5. Сравнительная характеристика биохимических показателей у пациентов со среднетяжелой формой COVID-19 в группах с высоким и нормальным уровнем ферритина

\begin{tabular}{|l|c|c|c|}
\hline \multicolumn{1}{|c|}{ Показатель } & $\begin{array}{c}\text { Группа с высоким уровнем } \\
\text { ферритина }\end{array}$ & $\begin{array}{c}\text { Группа с нормальным уровнем } \\
\text { ферритина }\end{array}$ & $\boldsymbol{U}$-критерий \\
\hline Альбумин, г/л & $33,85[30,2 ; 35,3]$ & $34[31,2 ; 35,6]$ & $p>0,05$ \\
\hline АЛТ, Ед/л & $45,7 *[30 ; 107]$ & $32,3[19,85 ; 56,8]$ & $p<0,05$ \\
\hline АСТ, Ед/л & $45,1^{*}[27,4 ; 54,2]$ & $27,9[21,83 ; 51,1]$ & $p<0,05$ \\
\hline Мочевина, ммоль/л & $7,55[4,75 ; 10,1]$ & $6,15[3,8 ; 8,13]$ & $p>0,05$ \\
\hline Креатинин, мкмоль/л & $89,5[76,25 ; 109]$ & $90[76 ; 98]$ & $p>0,05$ \\
\hline Глюкоза, ммоль/л & $6,9[5,78 ; 9,1]$ & $5,7[5,05 ; 6,73]$ & $p>0,05$ \\
\hline СРБ, мг/мл & $51,55^{*}[9,6 ; 83,95]$ & $11,8[5,9 ; 34,7]$ & $p<0,05$ \\
\hline Общий белок, г/л & $63,1 *[57,8 ; 69,1]$ & $70,25[67,5 ; 74,9]$ & $p<0,05$ \\
\hline Амилаза, Ед/л & $38^{*}[31,5 ; 75]$ & $59[42,5 ; 66]$ & $p<0,05$ \\
\hline Билирубин, мкмоль/л & $5,7[4,95 ; 8,2]$ & $8,1[5,2 ; 13,5]$ & $p>0,05$ \\
\hline
\end{tabular}


Таблица 6. Сравнительная характеристика иммунологических показателей у пациентов со среднетяжелой формой COVID-19 в группах с высоким и нормальным уровнем ферритина

\begin{tabular}{|c|c|c|c|}
\hline Показатель & $\begin{array}{c}\text { Группа с высоким уровнем } \\
\text { ферритина }\end{array}$ & $\begin{array}{c}\text { Группа с нормальным уровнем } \\
\text { ферритина }\end{array}$ & $U$-критерий \\
\hline $\mathrm{CD}^{+}, \%$ & $67[58,5 ; 72]$ & $75 *[71,5 ; 76,5]$ & $p<0,05$ \\
\hline $\mathrm{CD}^{+}, \bullet 10^{9} /$ л & $0,66[0,46 ; 0,97]$ & $1,13 *[0,81 ; 1,75]$ & $p<0,05$ \\
\hline $\mathrm{CD}^{+} \mathrm{CD}^{+}, \%$ & $42[33,5 ; 47]$ & $49 *[39,5 ; 53]$ & $p<0,05$ \\
\hline $\mathrm{CD}^{+} \mathrm{CD}^{+}, \bullet 10^{9} /$ л & $0,42[0,3 ; 0,7]$ & $0,63^{*}[0,51 ; 1,16]$ & $p<0,05$ \\
\hline $\mathrm{CD}^{+} \mathrm{CD}^{+}, \%$ & $24[13 ; 32,5]$ & $22[19,5 ; 32]$ & $p>0,05$ \\
\hline $\mathrm{CD}^{+} \mathrm{CD}^{+}, \bullet 10^{9} /$ л & $0,19[0,15 ; 0,3]$ & $0,32 *[0,26 ; 0,59]$ & $p<0,05$ \\
\hline ИРИ & $1,6[1,1 ; 3,25]$ & $2[1,28 ; 2,7]$ & $p>0,05$ \\
\hline $\mathrm{CD}_{16}, \%$ & $10[7,5 ; 17]$ & $11[6,5 ; 18,5]$ & $p>0,05$ \\
\hline $\mathrm{CD}_{16}{ }^{+}, \bullet 10^{9} /$ л & $0,15[0,06 ; 0,18]$ & $0,23 *[0,12 ; 0,29]$ & $p<0,05$ \\
\hline $\mathrm{CD}_{19}+\%$ & $19[11,5 ; 23]$ & $10 *[9 ; 16,5]$ & $p<0,05$ \\
\hline $\mathrm{CD} 19+^{+}, \bullet 10^{9} /$ л & $0,17[0,1 ; 0,21]$ & $0,16[0,11 ; 0,26]$ & $p>0,05$ \\
\hline $\operatorname{IgA,~г/л~}$ & $2,19[1,46 ; 2,83]$ & $1,9[1,66 ; 3,5]$ & $p>0,05$ \\
\hline $\operatorname{IgM}$, г/л & $0,95[0,71 ; 1,22]$ & $0,89[0,82 ; 1,1]$ & $p>0,05$ \\
\hline $\mathrm{IgG}$, г/л & $9,6[8,23 ; 10,73]$ & $10,9 *[9,4 ; 12,1]$ & $p<0,05$ \\
\hline
\end{tabular}

лимфоцитов и постоянство иммунорегуляторного индекса. Довольно интересны полученные данные о гуморальном звене адаптивного иммунного ответа. Так, относительное содержание В-лимфоцитов в 2 раза выше в группе с высоким содержанием ферритина. Однако уровень $\operatorname{IgG}$ в сыворотке выше в группе с нормальным уровнем ферритина (табл. 6).

\section{Обсуждение}

Внезапное появление и быстрое распространение новой коронавирусной инфекции и вызываемого ей COVID-19 поставило перед специалистами здравоохранения ряд задач, и одной из них является поиск возможных способов прогнозирования тяжелого течения COVID-19. Кроме того, патогенез тяжелых инфекций, вызванных коронавирусами, изучен недостаточно, однако среди исследователей есть понимание, что ключевую роль в развитии и исходе заболевания играют факторы, связанные с иммунной системой человека [13-15]. Выявление таких факторов позволит повысить эффективность не только прогноза течения, но и терапии COVID-19 [14-16].

В данной работе продемонстрировано, что ключевые изменения лабораторных показателей крови у больных среднетяжелой формой COVID-19 в первую очередь проявляются лимфопенией крови. Снижение относительного и абсолютного числа лимфоцитов достоверно ассоциируется с более тяжелым протеканием заболевания. Картина КТ с большей степенью поражения легких, симптомы интоксикации и потребность в кислороде возрастают пропорционально снижению данного показателя в группе с более высоким уровнем ферритина. Эти изменения полностью согласуются с данными литературы, где отмечалось, что лимфопения является прогностическим критерием для поступления в отделение интенсивной терапии [17]. Изменения биохимических показателей у пациентов с более тяжелой клинической картиной характеризовались также одновременным повышением уровней белков острой фазы: СРБ и ферритина. Выше мы уже отмечали, что и содержание общего белка в группе с высоким уровнем ферритина достоверно ниже. Чем это можно объяснить? Вероятно, это связано с большей интенсивностью катаболизма $\gamma$-глобулинов у данных пациентов. Лимфопения, безусловно, оказывает влияние и на выявленные изменения в иммунном статусе пациентов. Следует отметить признаки нарастающей дисфункции иммунной системы, заключающиеся в нарушении процессов созревания Т-лимфоцитов, снижения содержания Т-лимфоцитов, обладающих хелперной функцией, и инверсию иммунорегуляторного индекса у пациентов с высоким содержанием ферритина. Статистически достоверное увеличение содержания CD19+-лимфоцитов у них не приводит к усилению процессов антителогенеза. Снижение абсолютной численности ключевых субпопуляций лимфоцитов достоверно сопровождает утяжеление состояния больного и требует обязательной коррекции.

\section{Заключение}

Таким образом, полученные результаты подтверждают установленную ранее зависимость тяжести течения COVID-19 от уровня ферритина. При этом расшифрован иммунологический механизм, формирующий выявленную зависимость. У пациентов со среднетяжелыми формами COVID-19 и высоким уровнем ферритина отмечаются более выраженные дисрегуляторные процессы в иммунной системе, проявляющиеся в первую очередь нарушением процессов созревания Т-клеточного звена, а также усиленной пролиферацией В-лимфоцитов без адекватного увеличения процессов антителогенеза.

Вклад авторов. Концепция и дизайн исследования Сизякина Л.П.; сбор и обработка материала - Закурская В.Я., Скрипкина Н.А., Антонова Е.А.; написание текста, редактирование - Сизякина Л.П., Закурская В.Я.; окончательный вариант и целостность текста Сизякина Л.П. 


\section{- Литература}

1. Ситуация с COVID-19 в Европейском регионе BO3. Режим доступа: https:/who.maps.arcgis.com/apps/opsdashboard/ index.html\#/a19d5d1f86ee4d99b013eed5f637232d (дата обращения 12.08.2021)

2. Hanff T.C., Mohareb A.M., Giri J., Cohen J.B., Chirinos J.A. Thrombosis in COVID-19. Am J Hematol. 2020; 95 (12): 1578-1589. DOI: 10.1002/ajh.25982

3. Avila J, Long B, Holladay D, Gottlieb M. Thrombotic complications of COVID-19. Am J Emerg Med. 2021 Jan; 39: 213-8. DOI: https://www.doi.org/10.1016/j.ajem.2020.09.065

4. Martín Giménez V.M., InserraF., TajerC.D., Mariani J., FerderL., Reiter R.J., Manucha W. Lungs as target of COVID-19 infection: Protective common molecular mechanisms of vitamin D and melatonin as a new potential synergistic treatment. Life Sci. 2020; 254: 117808 DOI: https://www.doi.org/10.1016/j.lfs.2020.117808

5. Rokkas T. Gastrointestinal involvement in COVID-19: a systematic review and meta-analysis. Ann Gastroenterol. 2020; 33 (4): 355-65. DOI: https://www.doi.org/10.20524/aog.2020.0506

6. Li S.R., Tang Z.J., Li Z.H., Liu X. Searching therapeutic strategy of new coronavirus pneumonia from angiotensin-converting enzyme 2: the target of COVID-19 and SARS-CoV. Eur J Clin Microbiol Infect Dis. 2020; 39 (6): 1021-6. DOI: https://www.doi. org/10.1007/s10096-020-03883-y

7. Liu F., Li L., Xu M., Wu J., Luo D., Zhu Y., Li B., Song X., Zhou X. Prognostic value of interleukin-6, C-reactive protein, and procalcitonin in patients with COVID-19. J Clin Virol. 2020; 127: 104370. DOI: https://www.doi.org/10.1016/j.jcv.2020.104370

8. Sahu B.R., Kampa R.K., Padhi A., Panda A.K. C-reactive protein: A promising biomarker for poor prognosis in COVID-19 infection. Clin Chim Acta. 2020; 509: 91-4. DOI: https://www.doi. org/10.1016/j.cca.2020.06.013

9. Потемина Т.Е.,ВолковаС.А.,КузнецоваС.В.,ПерешеинА.В Общие вопросы метаболизма железа и патогенеза железодефицитной анемии. Вестник медицинского института «Реавиз». Реабилитация, Врач и Здоровье. 2020; (3): 125-37.

10. Шамов И.А., Гасанова П.О. Железо, абсорбция, транспорт. Вестник гематологии. 2016; 12 (1): 31-8.
11. Sallenave J.M., Guillot L. Innate Immune Signaling and Proteolytic Pathways in the Resolution or Exacerbation of SARS CoV-2 in Covid-19: Key Therapeutic Targets? Front Immunol 2020; 11: 1229. DOI: https://www.doi.org/10.3389/fimmu.2020. 01229

12. Yang L., Liu S., Liu J., Zhang Z., Wan X., Huang B., Chen Y., Zhang Y. COVID-19: immunopathogenesis and Immunotherapeutics. Signal Transduct Target Ther. 2020; 5 (1): 128. DOI: https://www.doi. org/10.1038/s41392-020-00243-2

13. Болдырева M.H. Вирус SARS-CoV-2 и другие эпидемические коронавирусы: патогенетические и генетические факторы развития инфекций. Иммунология. 2020; 41 (3): 197-205. DOI: https:/www.doi.org/10.33029/0206-4952-2020-41-3-197-205

14. Гудима Г.О., Хаитов Р.М., Кудлай Д.А., Хаитов М.Р. Молекулярно-иммунологические аспекты диагностики, профилактики и лечения коронавирусной инфекции. Иммунология. 2021; 42 (3) 198-210. DOI: https://doi.org/10.33029/0206-4952-2021-42-3-198210

15. Шатохина Е.А., Полонская А.С., Мершина Е.А., Серединина Е.М., Плисюк А.Г., Георгинова О.А., Краснова Т.Н., Павликова Е.П., Орлова Я.А., Синицын В.Е., Круглова Л.С., Камалов А.А. Возможность применения ингибиторов ИЛ-17 у пациентов c COVID-19: собственный опыт и обзор литературы. Иммунология. 2021; 42 (3): 243-53. DOI: https://doi.org/10.33029/0206-49522021-42-3-243-253

16. Khaitov M., Nikonova A., Shilovskiy I., Kozhikhova K., Kofiadi I., Vishnyakova L., Nikolsky A., Gattinger P., Kovchina V., Barvinskaya E., Yumashev K., Smirnov V., Maerle A., Kozlov I., Shatilov A., Timofeeva A., Andreev S., Koloskova O., Kuznetsova N., Vasina D., Nikiforova M., Rybalkin S., Sergeev I., Trofimov D., Martynov A., Berzin I., Gushchin V., Kovalchuk A., Borisevich S. Valenta R., Khaitov R., Skvortsova V. Silencing of SARS-CoV-2 with modified siRNA-peptide dendrimer formulation. Allergy. 2021. DOI: https://doi.org/10.1111/all.14850

17. Frater J.L., Zini G., d'Onofrio G., Rogers H.J. COVID-19 and the clinical hematology laboratory. Int J Lab Hematol. 2020; 42 (Suppl 1): 11-8. DOI: https://doi.org/10.1111/ijlh.13229

\section{References}

1. Situation with COVID-19 in Europe region WHO. URL: https:/who.maps.arcgis.com/apps/opsdashboard/index.html\#/a19d5d 1f86ee4d99b013eed5f637232d (date of access August 12, 2021)

2. Hanff T.C., Mohareb A.M., Giri J., Cohen J.B., Chirinos J.A. Thrombosis in COVID-19. Am J Hematol. 2020; 95 (12): 1578-89. DOI: https://doi.org/10.1002/ajh.25982

3. Avila J., Long B., Holladay D, Gottlieb M. Thrombotic complications of COVID-19. Am J Emerg Med. 2021; 39: 213-8. DOI: https://doi.org/10.1016/j.ajem.2020.09.065

4. Martín GiménezV.M., InserraF., TajerC.D., Mariani J.,FerderL., Reiter R.J., Manucha W. Lungs as target of COVID-19 infection: Protective common molecular mechanisms of vitamin D and melatonin as a new potential synergistic treatment. Life Sci. 2020; 254: 117808. DOI: https://doi.org/10.1016/j.1fs.2020.117808

5. Rokkas T. Gastrointestinal involvement in COVID-19: a systematic review and meta-analysis. Ann Gastroenterol. 2020; 33 (4): 355-65. DOI: https://doi.org/10.20524/aog.2020.0506

6. Li S.R., Tang Z.J., Li Z.H., Liu X. Searching therapeutic strategy of new coronavirus pneumonia from angiotensin-converting enzyme 2 the target of COVID-19 and SARS-CoV. Eur J Clin Microbiol Infect Dis 2020; 39 (6): 1021-6. DOI: https://doi.org/10.1007/s10096-020-03883-y

7. Liu F., Li L., Xu M., Wu J., Luo D., Zhu Y., Li B., Song X., Zhou X. Prognostic value of interleukin-6, C-reactive protein, and procalcitonin in patients with COVID-19. J Clin Virol. 2020; 127 104370. DOI: https://doi.org/10.1016/j.jcv.2020.104370

8. Sahu B.R., Kampa R.K., Padhi A., Panda A.K. C-reactive protein: A promising biomarker for poor prognosis in COVID-19 infection. Clin Chim Acta. 2020; 509: 91-4. DOI: https://doi. org/10.1016/j.cca.2020.06.013

9. Potemkina T., Volkova S., Kuznetsova S., Pereshin A. General issues of iron metabolism and pathogenesis of iron deficiency anemia Bulletin medical university «Reviz»: reabilitation, doctor and health 2020; (3): 125-37. (in Russian)

10. Shamov I., Gasanova P. Iron, absorption, transportation. Hematology bulletin. 2016; 12 (1): 31-8. (in Russian)
11. Sallenave J.M., Guillot L. Innate Immune Signaling and Proteolytic Pathways in the Resolution or Exacerbation of SARSCoV-2 in Covid-19: Key Therapeutic Targets? Front Immunol. 2020; 11: 1229. DOI: https://doi.org/10.3389/fimmu.2020.01229

12. Yang L., Liu S., Liu J., Zhang Z., Wan X., Huang B., Chen Y., Zhang Y. COVID-19: immunopathogenesis and Immunotherapeutics. Signal Transduct Target Ther. 2020; 5 (1): 128. DOI: https://doi org/10.1038/s41392-020-00243-2

13. Boldyreva M.N. SARS-CoV-2 virus and other epidemic coronaviruses: pathogenetic and genetic factors of infection development. Immunologiya. 2020; 41 (3): 197-205. DOI: https://doi org/10.33029/0206-4952-2020-41-3-197-205 (in Russian)

14. Gudima G.O., Khaitov R.M., Kudlay D.A., Khaitov M.R. Molecular immunological aspects of diagnostics, prevention and treatment of coronavirus infection. Immunologiya. 2021; 42 (3): 198-210. DOI https://doi.org/10.33029/0206-4952-2021-42-3-198-210 (in Russian)

15. ShatokhinaE.A.,PolonskaiaA.S.,MershinaE.A.,SeredeninaE.M., Plisyuk A.G., Georginova O.A., Krasnova T.N., Pavlikova E.P., Orlova Ya.A., Sinitsyn V.E., Kruglova L.S., Kamalov A.A. Possible role of anti-IL17 drugs in the management of COVID-19 - our own experience and literature review. Immunologiya. 2021; 42 (3): 243-53. DOI: https:// doi.org/10.33029/0206-4952-2021-42-3-243-253 (in Russian)

16. Khaitov M., Nikonova A., Shilovskiy I., Kozhikhova K., Kofiadi I., Vishnyakova L., Nikolsky A., Gattinger P., Kovchina V., Barvinskaya E., Yumashev K., Smirnov V., Maerle A., Kozlov I., Shatilov A., Timofeeva A., Andreev S., Koloskova O., Kuznetsova N., Vasina D., Nikiforova M., Rybalkin S., Sergeev I., Trofimov D., Martynov A., Berzin I., Gushchin V., Kovalchuk A., Borisevich S., Valenta R., Khaitov R., Skvortsova V. Silencing of SARS-CoV-2 with modified siRNA-peptide dendrimer formulation. Allergy. 2021. DOI: https://doi.org/10.1111/all.14850

17. Frater J.L., Zini G., d'Onofrio G., Rogers H.J. COVID-19 and the clinical hematology laboratory. Int J Lab Hematol. 2020; 42 (Suppl 1): 11-8. DOI: https://doi.org/10.1111/ijlh.13229 


\section{Сведения об авторах}

Сизякина Людмила Петровна - д-р мед. наук, проф., зав. каф. клинической иммунологии и аллергологии ФГБОУ ВО РостГМУ Минздрава России, Ростов-на-Дону, Российская Федерация E-mail: msiziakina@mail.ru http://orcid.org/0000-0001-5716-4397

Закурская Вита Яковлевна - ассистент каф. клинической иммунологии и аллергологии ФГБОУ ВО РостГМУ Минздрава России, Ростов-на-Дону, Российская Федерация

E-mail: vias.92@mail.ru

http://orcid.org/0000-0003-0837-1538

Скрипкина Надежда Анатольевна - врач-инфекционист моноинфекционного госпиталя № 1 МБУЗ «ГБ № 1 им. Н.А. Семашко», Ростов-на-Дону, Российская Федерация

E-mail: pers 348@mail.ru

http://orcid.org/0000-0003-0165-6805

Антонова Елена Алексеевна - начальник отдела качества лабораторных исследований МБУЗ «ГБ № 1 им. Н.А. Семашко», Ростов-на-Дону, Российская Федерация

E-mail: antonova.lab@gb-1.ru

http://orcid.org/0000-0003-4580-0020

\section{Authors' information}

Lyudmila P. Sizyakina - MD, PhD, Prof., Head of the Clinical Immunology and Allergology Chair, RostSMU, MOH of Russia, Rostov-on-Don, Russian Federation

E-mail: msiziakina@mail.ru

http://orcid.org/0000-0001-5716-4397

Vita Ya. Zakurskaya - Assistant of the Department of Clinical Immunology and Allergology, RostSMU, MOH of Russia, Rostov-on-

Don, Russian Federation

E-mail: vias.92@mail.ru

http://orcid.org/0000-0003-0837-1538

Nadezhda A. Skripkina - Infectious Disease Specialist at the Monoinfection Hospital No. 1 of the Semashko City Hospital No. 1, Rostov-on-Don, Russian Federation

E-mail: pers348@mail.ru

http://orcid.org/0000-0003-0165-6805

Elena A. Antonova - Head of the Laboratory Quality Research Department of the Semashko City Hospital No. 1, Rostov-on-Don, Russian Federation

E-mail: antonova.lab@gb-1.ru

http://orcid.org/0000-0003-4580-0020 